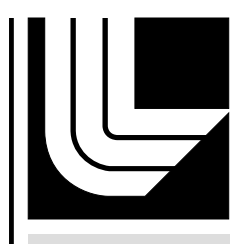

LAWRENCE LIVERMORE NATIO N A L LABORATORY

SAFETY AND SENSITIVITY OF NITROGLYCERINE (NG)

MIXTURES

P. C. Hsu, G. Hust, R. Schmidt

November 2, 2012 
This document was prepared as an account of work sponsored by an agency of the United States government. Neither the United States government nor Lawrence Livermore National Security, LLC, nor any of their employees makes any warranty, expressed or implied, or assumes any legal liability or responsibility for the accuracy, completeness, or usefulness of any information, apparatus, product, or process disclosed, or represents that its use would not infringe privately owned rights. Reference herein to any specific commercial product, process, or service by trade name, trademark, manufacturer, or otherwise does not necessarily constitute or imply its endorsement, recommendation, or favoring by the United States government or Lawrence Livermore National Security, LLC. The views and opinions of authors expressed herein do not necessarily state or reflect those of the United States government or Lawrence Livermore National Security, LLC, and shall not be used for advertising or product endorsement purposes.

This work performed under the auspices of the U.S. Department of Energy by Lawrence Livermore National Laboratory under Contract DE-AC52-07NA27344. 


\title{
Safety and Sensitivity of Nitroglycerine (NG) Mixtures
}

\author{
P. C. Hsu, G. Hust, and Robert Schmidt \\ Energetic Materials Center \\ Lawrence Livermore National Laboratory, Livermore, CA USA
}

October 24, 2012

\begin{abstract}
Small scale (SSST) safety tests were conducted to determine impact sensitivity, friction sensitivity and spark sensitivity of nitroglycerine (NG) and its mixtures. The tests were done for the following formulations (totally 9): NG (1\% stabilizer), NG with diluents (acetone and triacetin), and mixture of $\mathrm{NG}$ and nitrocellulose (NC). Aging study was also performed on NG/NC mixture to determine the effect of aging on sensitivity. The test results are summarized in this report.
\end{abstract}

Keywords: Explosives, impact sensitivity, drop hammer, friction sensitivity, spark sensitivity, nitroglycerine, and nitrocellulose. 


\section{INTRODUCTION}

Nitroglycerin (NG) is fairly sensitive to impact and it often is diluted with solvents to reduce its sensitivity for handling safety. Mixtures of NG and NC are popular for specific applications. This report presents the test results of $\mathrm{NG}$ and NG-NC mixtures with standard techniques used at LLNL and other laboratories (LANL, SNL, IH and Tyndall) in which explosives are studied.

\section{METHOD}

Small-scale sensitivity testing was done to determine material response to various stimuli including impact, friction, and static spark. These tests, briefly described below, provide parameters for safety in handling.

\subsection{Drop Hammer (impact sensitivity)}

ERL Type 12 drop hammer equipment at LLNL, shown in Figure 1, was used to determine the impact sensitivity. [1] The equipment includes a 2.5-kg drop weight, a striker (upper anvil, $2.5 \mathrm{~kg}$ for solid samples and $1.0 \mathrm{~kg}$ for liquid samples), a bottom anvil, a microphone sensor, and a peakmeter. For each drop, sample (35 mg for solids or 35 microliter for liquids) is placed on the bottom anvil surface and impacted by the drop weight from different heights. Signs of reactions upon impact are observed and recorded. These signs include noises, flashes or sparks, smoke, pressure, gas emissions, temperature rise due to exothermic reaction, color change of the sample, and changes to the anvil surface (noted by inspection). For solid samples, a "GO" was defined as a microphone sensor (for noise detection) response of $\geq 1.3 \mathrm{~V}$ as measured by a peakmeter. The higher the $\mathrm{DH}_{50}$ values, the lower the impact sensitivity. The method used to calculate $\mathrm{DH}_{50}$ values is the "up and down" or Bruceton method [2,3]. PETN and RDX have impact sensitivities of 15 and $35 \mathrm{~cm}$, respectively. TATB has impact sensitivity more than $177 \mathrm{~cm}$. For liquid samples, a "GO" was determined by the noise levels as measured by the peakmeter, appearance of flashes, temperature rise of the anvil, and visual inspection of the anvil surface. Two liquid samples TMETN and FEFO have impact sensitivities of 14 and $32 \mathrm{~cm}$, respectively.

\subsection{Frictional Sensitivity}

A BAM friction sensitivity test machine, as shown in Figure 2, was used to determine the frictional sensitivity.[4] The system uses a fixed porcelain pin and a movable porcelain plate that executes a reciprocating motion. Weight affixed to a torsion arm allows for a variation in applied force between $0.5 \mathrm{~kg}$ to 36.0 $\mathrm{kg}$. The relative measure of the frictional sensitivity of a material is based upon the smallest load $(\mathrm{kg}) \mathrm{at}$ which reaction occurs for a 1-in-10 series of attempts. The lower the load values, the higher the frictional sensitivity. PETN has a frictional sensitivity of $6.4 \mathrm{~kg}$.

\subsection{Spark Sensitivity}

The static spark machine at LLNL is used to evaluate the electrostatic discharge hazards (human ESD) associated with the handling of explosives.[5] The machine was custom-built almost 30 years ago and consists of a capacitor bank (up to 20,000 pF), a voltage meter, and a discharge circuit, as shown in Figure 3. An adjustable resistor up to $510 \mathrm{ohms}$ (chosen to simulate human body) is wired to the discharge circuit. A 5-mg sample is placed in a Teflon washer sealed to a steel disc and covered with a Mylar tape. High static voltage (up to $10 \mathrm{kv}$ ) is applied and discharged to the sample. Evidence of reaction is judged from the condition of Mylar tape, smokes, and color change of the sample. Voltage, capacitance, and resistance can be adjusted to achieve the desired static energy. The results obtained are expressed as a zero in 10 or one-inten at a specific voltage and joules. One reaction in ten trials at $\leq 0.25$ joules is considered spark-sensitive. Primary explosives show reaction at 0.1 joule. 


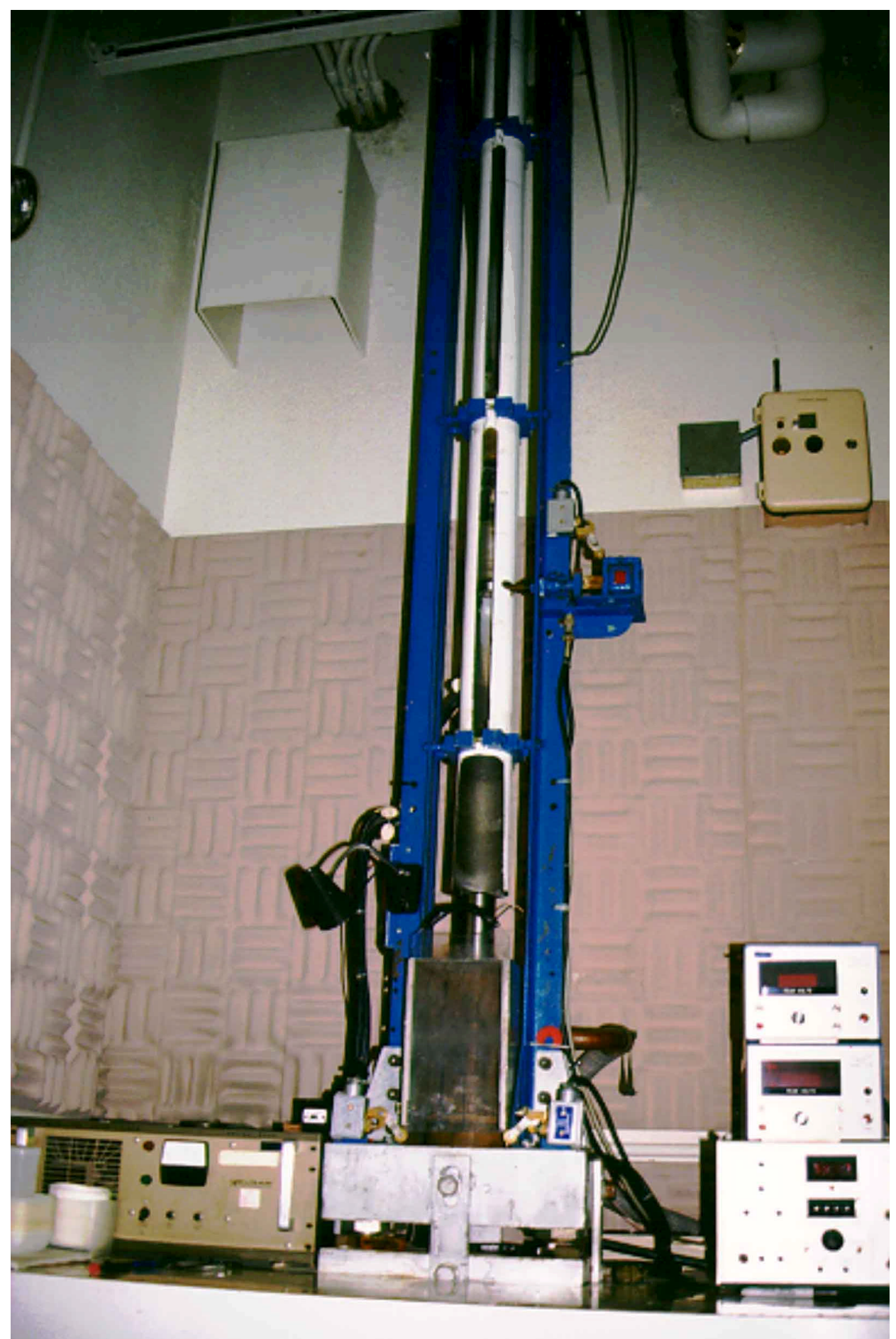

Figure 1. Drop hammer system at LLNL 

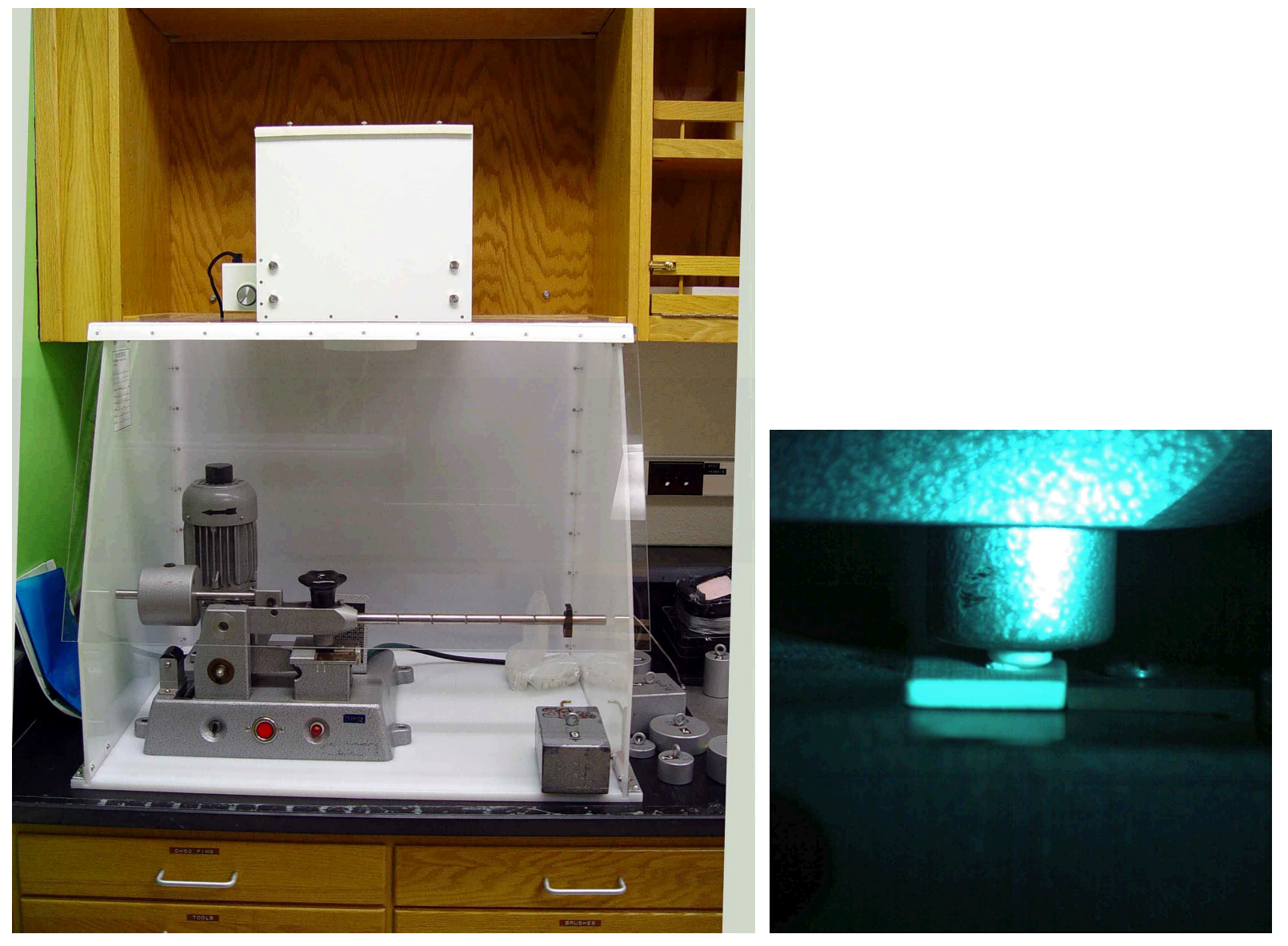

Figure 2. Friction sensitivity test machine; (a) front view, left; (b) pin and plate with sample in between in a close-up view, right. 


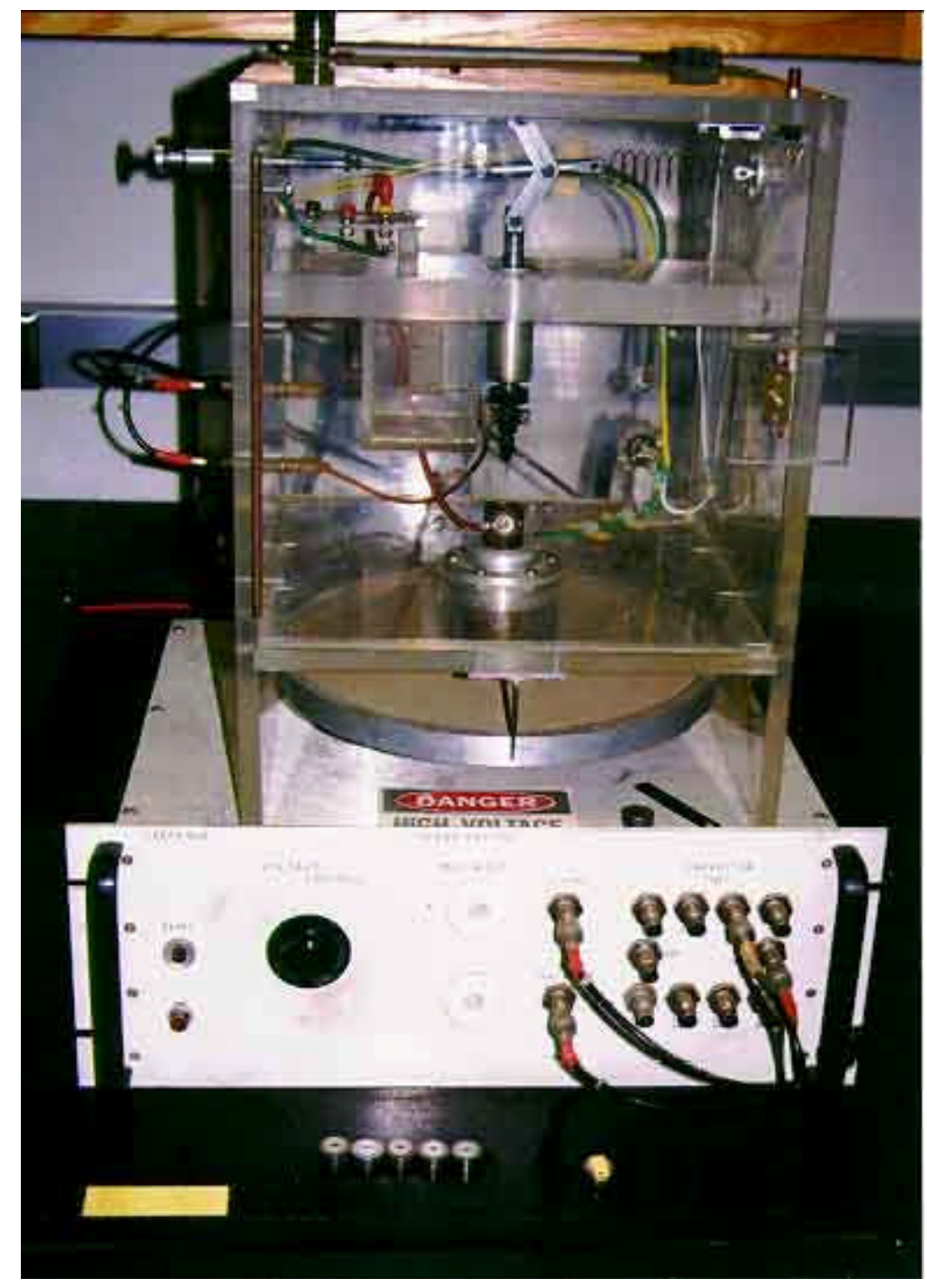

Figure 3. Spark test system 


\subsection{Sample compositions}

All 9 mixtures were prepared and tested for their sensitivities. Table 1 lists compositions of the mixtures. Mixture 9 was chosen for aging study.

Table 1. Composition* of Mixtures 1 to 9

\begin{tabular}{|c|c|c|c|c|c|c|c|c|c|}
\hline & Mix 1 & Mix 2 & Mix 3 & Mix 4 & Mix 5 & Mix 6 & Mix 7 & Mix 8 & Mix 9** $^{* 1}$ \\
\hline $\begin{array}{c}\text { Surface } \\
\text { for impact } \\
\text { testing }\end{array}$ & $\begin{array}{c}\text { Bare } \\
\text { anvil }\end{array}$ & $\begin{array}{c}\text { Bare } \\
\text { anvil }\end{array}$ & $\begin{array}{c}\text { Bare } \\
\text { anvil }\end{array}$ & $\begin{array}{c}\text { Bare } \\
\text { anvil }\end{array}$ & $\begin{array}{c}\text { Bare } \\
\text { anvil }\end{array}$ & $\begin{array}{c}\text { Bare } \\
\text { anvil }\end{array}$ & $\begin{array}{c}\text { Bare } \\
\text { anvil }\end{array}$ & $\begin{array}{c}\text { Bare } \\
\text { anvil }\end{array}$ & $\begin{array}{c}\text { 120 grit } \\
\text { sand } \\
\text { paper }\end{array}$ \\
\hline NG & $99 \%$ & $88 \%$ & $80 \%$ & $71 \%$ & $88 \%$ & $79 \%$ & $71 \%$ & $59 \%$ & $80 \%$ \\
\hline NC & $1 \%$ & & & & & & & & $20 \%$ \\
\hline $\begin{array}{c}\text { Stabilizer } \\
\text { (NDPA) }\end{array}$ & & & & & & & & & \\
\hline \multicolumn{2}{|l|}{ Acetone } & $12 \%$ & $20 \%$ & $29 \%$ & & $21 \%$ & & & \\
\hline
\end{tabular}

\section{RESULTS}

\subsection{Sensitivities of mixtures}

The 9 mixtures were freshly prepared (mixing) immediately before performing the sensitivity testing except for the aging study. Sample size of 35 microliters (liquids) or $35 \mathrm{mg}$ (gel) was precisely measured and placed on the bottom anvil surface (bare anvil for mixtures 1 to 8,120 grit sand paper for mixture 9) for impact sensitivity testing. The drop weight was set at different heights for impacting the samples. Signs of reaction for determining "GO" or "NO-GO" were noise levels recorded by the peakmeter, flashes, temperature measurement with an IR probe, and changes noted through visual inspection of anvil surface. The tests were performed at ambient condition $\left(72^{\circ} \mathrm{F}, 20 \%\right.$ R.H.) by the same technician. Figure 4 shows a "GO" event with an appearance of flashes as the drop weight impacted the sample. The impact sensitivity test results are listed in Table 2. Impact sensitivities for some commonly used explosives are also listed in the table for comparison. Table 2 shows that neat NG without dilution is impact-sensitive. But after diluted with acetone or triacetin, the impact sensitivities (mix 2 to 8 ) were similar to those of secondary explosives, values ranging from $15 \mathrm{~cm}$ to more than $177 \mathrm{~cm}$.

Since neat NG with $1 \%$ stabilizer NDPA was not friction sensitive and not spark sensitive, no friction and spark tests were performed on diluted mixtures 2 to 8 . Table 2 also lists results of frictional sensitivity tests and spark sensitivity tests. All mixtures tested showed no reaction to spark. 
Table 2. Impact sensitivities, friction sensitivity, and spark sensitivity for the 9 mixtures

\begin{tabular}{|c|c|c|c|}
\hline Mixtures and compositions & $\begin{array}{c}\text { Impact sensitivity, } \\
\text { DH }_{\mathbf{5 0}}, \mathbf{c m}\end{array}$ & $\begin{array}{c}\text { Friction } \\
\text { sensitivity }\end{array}$ & Spark sensitivity \\
\hline Mix 1, NG 99\%, 1\% NDPA & 9.1 & $1 / 10 @ 27 \mathrm{~kg}$ & $0 / 10$ @ 1.0 Joule \\
\hline Mix 2, NG 88\%, acetone 12\% & 15.6 & NT* & NT \\
\hline Mix 3, NG 80\%, acetone 20\% & 48.1 & NT & NT \\
\hline Mix 4, NG 71\%, acetone 29\% & 154.5 & NT & NT \\
\hline Mix 5, NG 88\%, triacetin 12\% & 14.6 & NT & NT \\
\hline Mix 6, NG 79\%, triacetin 21\% & 58.6 & NT & NT \\
\hline Mix 7, NG 71\%, triacetin 29\% & 140.9 & NT & NT \\
\hline Mix 8, NG 59\%, triacetin 41\% & $>177$ & NT & NT \\
\hline Mix 9, NG 80\%, NC 20\% & 13.3 & $1 / 10 @ 9.6 \mathrm{~kg}$ & $0 / 10$ @ 1.0 Joule \\
\hline PETN & 15 & $1 / 10 @ 6.4 \mathrm{~kg}$ & $0 / 10 @ 1.0$ Joule \\
\hline HMX & 32 & $1 / 10 @ 11.6 \mathrm{~kg}$ & $0 / 10 @ 1.0$ Joule \\
\hline RDX & 35 & $1 / 10 @ 12.4 \mathrm{~kg}$ & $0 / 10 @ 1.0$ Joule \\
\hline TATB & $>177$ & $0 / 10 @ 36 \mathrm{~kg}$ & $0 / 10 @ 1.0$ Joule \\
\hline
\end{tabular}

* NT- not tested because diluted nitroglycerine was not expected to be friction and spark sensitive

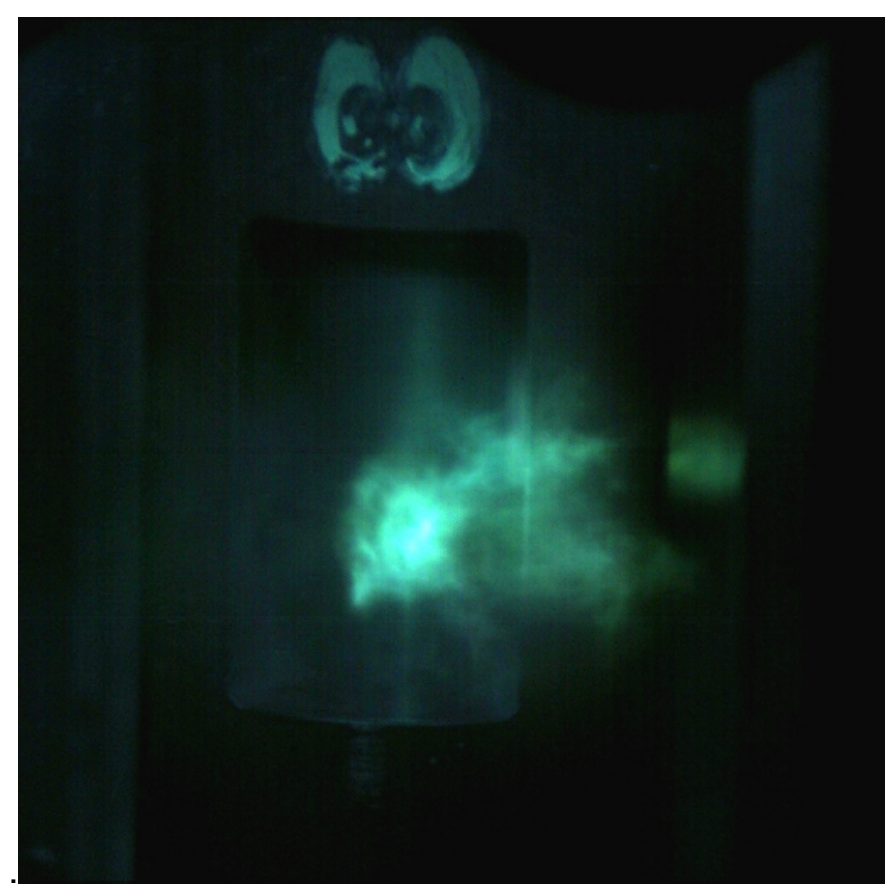

Figure 4. A "GO" event observed during the impact sensitivity test; flashes appeared as the drop weight impacted the sample.

\subsection{Effect of material aging on impact sensitivity}

After NC was added to NG, the mixture (mixture 9) jelled slowly and the viscosity and density changed. In an effort to understand the effect of aging on its handling safety, we conducted a series of impact testing on 
aged samples with the results shown in Table 3 . Table 3 shows the sample became very impact sensitive after it aged for a few hours $\left(\mathrm{DH}_{50}\right.$ dropped to $7.3 \mathrm{~cm}$ in 4 hours). After 4 days, the impact sensitivity was $2.0 \mathrm{~cm}$, very sensitive to handle. This was probably due to the formation of air bubbles (up to several hundred microns) as a result of nitrocellulose dissolution into nitroglycerin (see Figure 5), making the sample more porous and hence increased the impact sensitivity. No friction and spark testing was performed on the aged samples because no sufficient amount of aged samples were available at the time.

Table 3. Effect of aging on sensitivities of NG/NC mixture $(80 \% / 20 \%)$

\begin{tabular}{|c|c|c|c|}
\hline Aging time & $\begin{array}{c}\text { Impact sensitivity, } \\
\mathbf{D H}_{\mathbf{5 0}}, \mathbf{c m}\end{array}$ & $\begin{array}{c}\text { Friction } \\
\text { sensitivity }\end{array}$ & Spark sensitivity \\
\hline 1 hour & 13.3 & $1 / 10 @ 9.6 \mathrm{~kg}$ & $0 / 10 @$ @ 1.0 Joule \\
\hline 3 hours & 11.1 & $\mathrm{NT}$ & $\mathrm{NT}$ \\
\hline 4 hours & 7.3 & $\mathrm{NT}$ & $\mathrm{NT}$ \\
\hline 23 hours & 4.6 & $\mathrm{NT}$ & $\mathrm{NT}$ \\
\hline 4 days & 2.0 & $\mathrm{NT}$ & $\mathrm{NT}$ \\
\hline
\end{tabular}

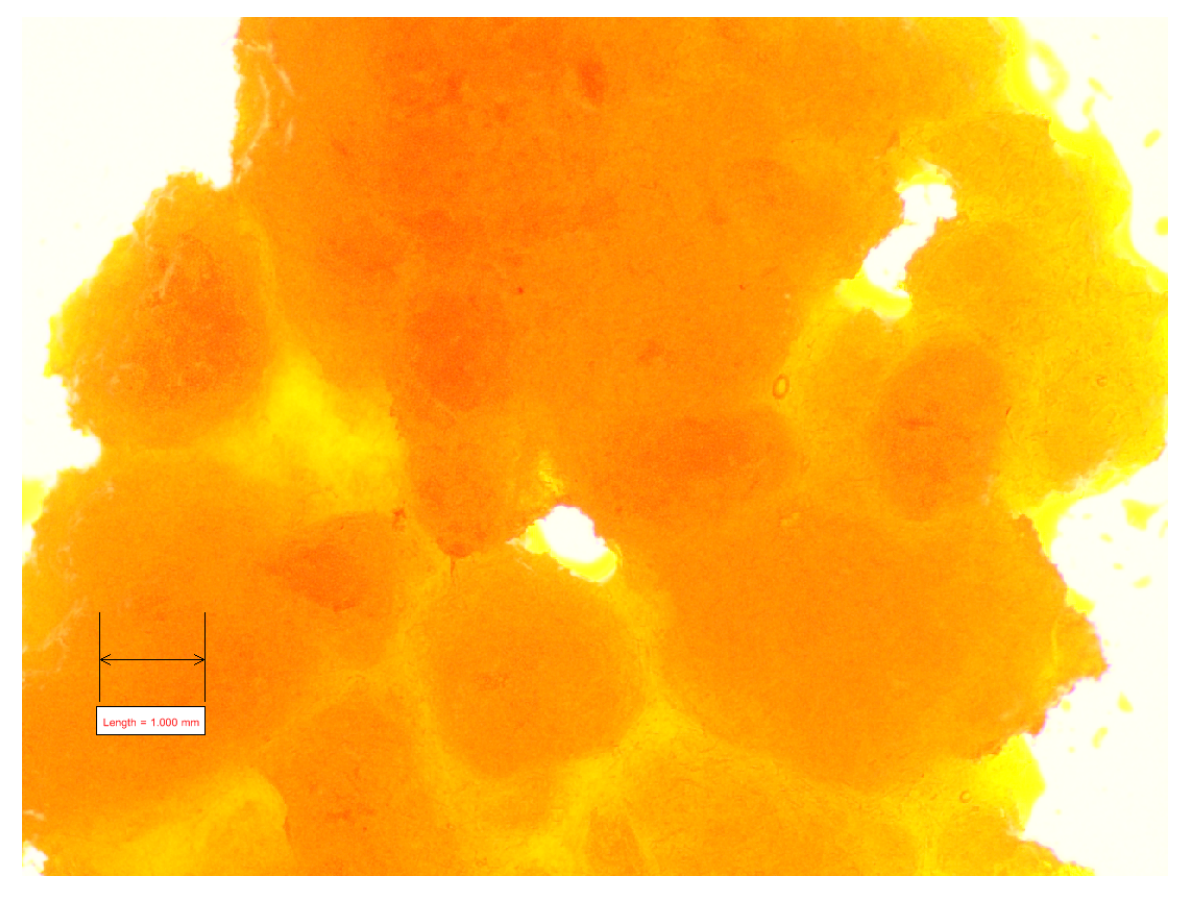

Figure 5a. NG/NC mixture after one hour of preparation; $\mathrm{DH}_{50}$ was $13.3 \mathrm{~cm}$. 


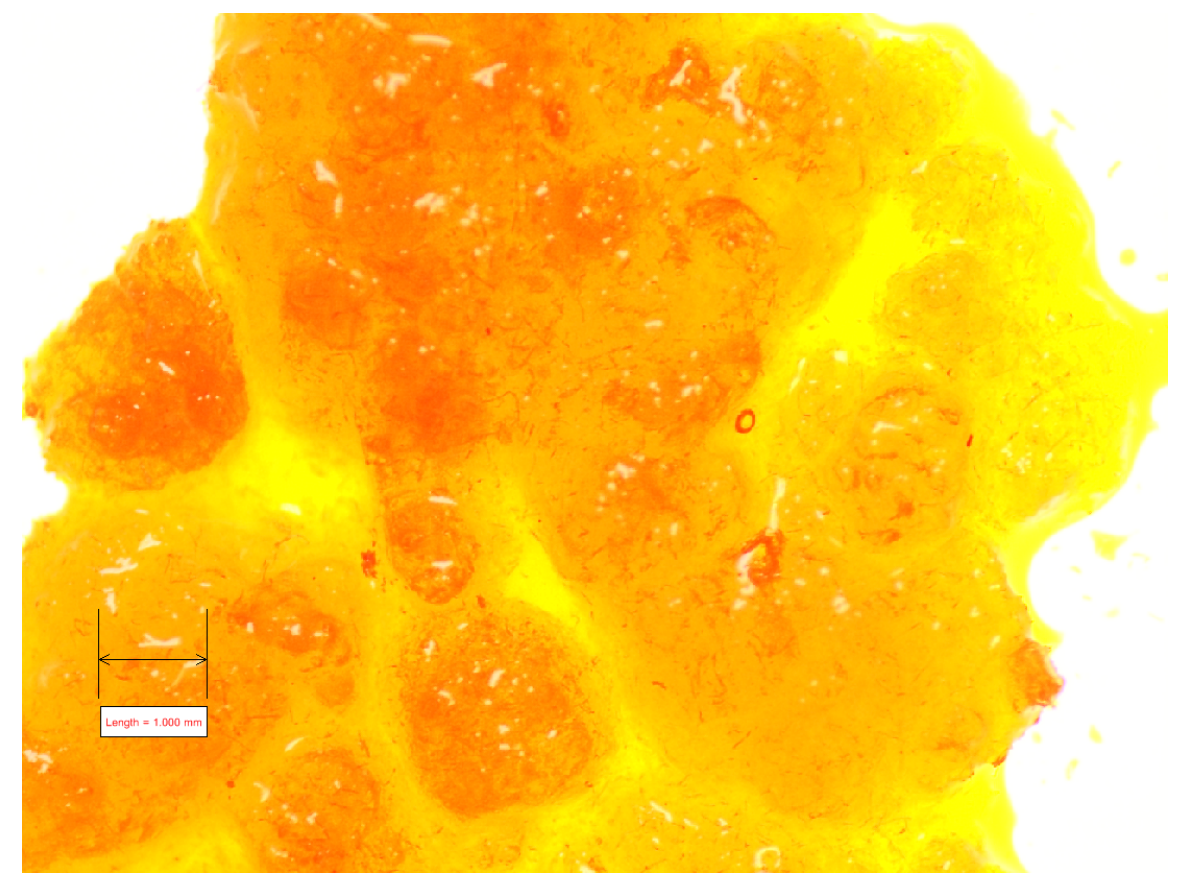

Figure 5b. NG/NC mixture after aging for 23 hours, many air bubbles formed; $\mathrm{DH}_{50}$ was $4.6 \mathrm{~cm}$.

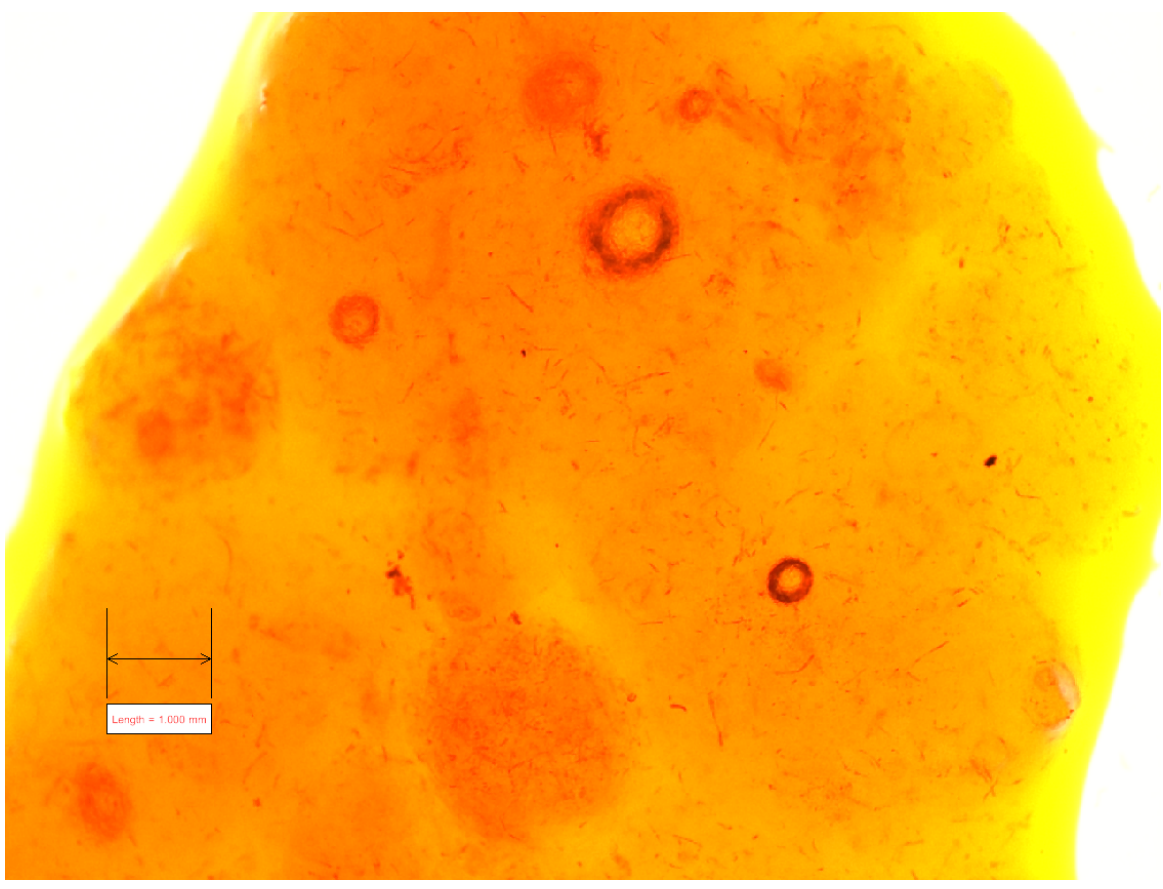

Figure 5c. NG/NC mixture after aging for 4 days, larger air bubbles were visible; $\mathbf{D H}_{50}$ was $2.0 \mathrm{~cm}$. 


\section{CONCLUSIONS}

$8 \mathrm{NG}$ /diluents mixtures and $1 \mathrm{NG} / \mathrm{NC}$ mixture were formulated and sent for evaluation for their sensitivities to various stimuli with LLNL's drop hammer (drop weight) system, friction test machine, and the spark test machine. These tests were performed on the samples immediately after formulation, thus eliminating the variable of side reactions. Neat nitroglycerine with $1 \%$ stabilizer NDPA was impact sensitive. After dilution, test results showed that $\mathrm{DH}_{50}$ values for the $\mathrm{NG} /$ diluent mixtures were between $15 \mathrm{~cm}$ and greater than $177 \mathrm{~cm}$, behaved like secondary explosives. All mixtures tested showed no reaction to spark testing. Gelled NG/NC mixture (80\%/20\%) was somewhat impact sensitive when tested right after formulation but

not sensitive to friction and spark. Impact sensitivity of gelled NG/NC increased greatly after a few hours of aging. In 4 days, the impact sensitivity of the sample was only $2 \mathrm{~cm}$. it must be handled very carefully. More experiments are recommended to determine the effect of aging on friction sensitivity and spark sensitivity of gelled NG/NC samples.

\section{NOMENCLATURE}

BAM Bundesanstalt für Materialprüfungen

DH drop hammer values

HMX Cyclotetramethylenetetra-nitramine

NC Nitrocellulose

NG Nitroglycerine

PETN Pentaerythritol tetranitrate

$\mathrm{pF} \quad$ pico-Faraday

RDX Cyclotrimethylenetrinitramine

TATB 1,3,5-triamino-2,4,6-trinitrobenzene

\section{REFERENCES}

1. Simpson, L. R. and Foltz, M.F., "LLNL Small-Scale Drop-Hammer Impact Sensitivity Test,” UCRL-ID119665, 1995.

2. Dixon, W.J. and Massey, F.J., "Introduction to Statistical Analysis, 2nd ed., McGraw-Hill, New York, pp 318$327,1957$.

3. Dixon, W.J., "The Up and Down Method for Small Samples," J. Am. Statistical Assoc., 60, pp 967-978, 1965.

4. Simpson, L.R. and Foltz, M.F., "LLNL Small-Scale Friction Sensitivity (BAM) Test,” UCRL-ID-124563, 1996.

5. Simpson, L.R. and Foltz, M.F., "LLNL Small-Scale Static Spark Machine: Static Spark Sensitivity Test," UCRL-ID-135525, 1999. 